is controversial Kuhn makes better use of his historical examples. For an account of how some early scientists went about their work, with discreet methodological inferences drawn where necessary, the best recommendation remains the series of "Harvard Case Histories" edited by J. B. Conant.

RoBert Maycock

\section{THOUGHTS ON DREAMS}

Dream Psychology and the New Biology of Dreaming Edited by Milton. Kramer, in collaboration with Roy M. Whitman, Bill J. Baldridge and Paul H. Ornstein. Pp. xvi+459. (Thomas: Springfield, Illinois, July 1969.) $\$ 17$.

Here is an American book devoted to dreams, with contributions from thirty-five contributors of varying schools of thought. Familiar Freudian attitudes are followed by the less familiar Adlerian position. Here we may find clearly stated the existentialist view that the dream is not a disguise for secret wishes of the waking life, nor an inferior and vague expression of transitory physical or psychological states, but an open, intense and cuthentic experience which should be understood without waking state prejudices. Not all viewpoints are given space, and noticeable was the absence of David Foulkes, who has made the most striking American studies of droaming in recent years.

The recent increase in knowledge of the physiology of sleep and of the dreaming state has revived interest in the study of dreams themselves, and the purpose of this book is to summarize the new physiological knowledge and concentrate at length on the psychology of the drcam. Whitman considers it impossiblo any longer to accept Freud's dictum that dreams are guardians of sleep because it is inconsistent with the periodicity and rhythmicity of the REM sleep period with its accompanying dreaming, a period in which, Jolyon West suggests, brain anabolic processes are in progress.

There is emphasis on the fact that when dreams are collected by laboratory awakening techniques they are influenced in content by the setting, and by the relation. ship between the dreamer and the observer. A difference of sex between the two will mobilize heterosexual problems which will become manifest in the dreams. Anxiety. provoking films viewed before sleep are followed by dreams having more anxiety content-not surprising when one recalls the wartime literature on battle dreams. Bonime, a culturalist (that is to say, a psychiatrist who works on the empirical assumption that all behaviour is determined by cultural or social forces, and not by instinctive and individual forces), comments that while there are many studies of dream imagery and of the meaning of the dream content, there have been few of the affect or mood which moulds and pervades the dream.

Just as pre-sleep anxiety is followed by dream anxiety, so, says Cartwright, those who express their impulses in waking life will express more hostility and sexuality in dreams. This could support the view that dream-life does not serve a complementary role, filling up what is lacking in our daytime life, but merely shows continuity with waking life.

The nervous irritability of the early menstrual period is reflected in an increase of dream aggression, initiated by the dreamer herself, during the time of menstruation, but with the accompaniment of an increase in friendly inter-personal dream interactions initiated by the dreamer herself.

The most important methodological advance discussed in the book is described by Calvin. Hall and Van der Castle; namely, dream content analysis by methods which enable dream content to be scored according to large numbers of criteria, with high inter-scorer reliability. Particularly powerful is contingency analysis which enables one to determine what eloments occur together more often than would be expected by chance. Clinical impressions were that a man was preoccupied with bowel functions and contingency analysis showed that such elements as tunnel, pressure, explosion, brown, dirty, water and empty occurred in the same dream more frequently than would be expected by chance.

At the end of the book comes what I hope I may be permitted to call a characteristically American suggestion, that children should be trained to use their dreams as an access to their inner life in order that they might find no attraction in hallucinogens like LSD.

I was a bit disappointed with the quality of some chapters, but it is a useful book, with potential ideas for research students.

IAN OsWALD

\section{DIAGNOSIS OF A ROYAL MALADY}

\section{George III and the Mad-Business}

By Ida Macalpino and Richard Hunter. Pp. xv +407. (Allen Lane (The Penguin Press): London, November 1969.) $70 \mathrm{~s}$.

To make a medical diagnosis from historical data is always a risky business. And yet there are many publications on problems as diverse as the Plague of Athens and Henry VIII's ulcerous legs. Such "armchair diagnoses" are rarely justifiable because the information available is usually inadequate for a precise conclusion to be reached. This book, however, is one of the very few instances where the technique has been successfully and brilliantly used.

The study of George III made by Drs Macalpine and Hunter is deservedly well known. They claim that his intermittent mental derangement was caused by a rare hereditary defect of porphyria metabolism producing a wide range of episodic physical as well as mental symptoms. Sufferers from porphyria are not insane in the usual sense of the word, for they have attacks of "madness" but are normal between them. The traditional view of George III is that he had bouts of insanity which even. tually engulfed him completely. The authors call this "the lore of the Mad King" and then proceed to demolish it. If one examines closely all the clinical and collateral evidence, with the disease, porphyria, in mind, it is possible, without Procrustean efforts, to conclude that this must be the diagnosis, with the addition of senility in later life. One can also readily understand how this bizarre condition must have confused the attendant physicians and that it could easily do so today. With incredible industry and thoroughness the authors have drawn upon a mass of data from a diversity of sources. There is new as well as previously published material, with many contemporary and eyewitness accounts. Some writers would have used each opportunity to force home the diagnosis, but Macalpine and Hunter use the much more effective and subtler mothod of allowing the adequately articulate material to speak for itself.

The first part of the book contains this evidence and from it a vivid picture is derived, not only of the King's illness but also of contemporary modicine, especially psychiatry, and of the medical profession itself and the conflicts associated with royal patronage. At this stage one begins to agree with the proposed clinical interpretation, but the authors now proceed to supply even more confirmation. They have studied carefully the Houses of Hanover, Stuart, Tudor and Prussia, and have not only found the disease in other members but also in four living descendants, thus providing the most vital support for their contentions. As the authors point out, many studies of reinterpretation with the royal malady in mind will now be needed; for example, Mary Queen of Scots, James VI and I, and Caroline Matilda, Queen of Denmark and Norway, among others.

The authors also suggest that Georgo III's illness 